
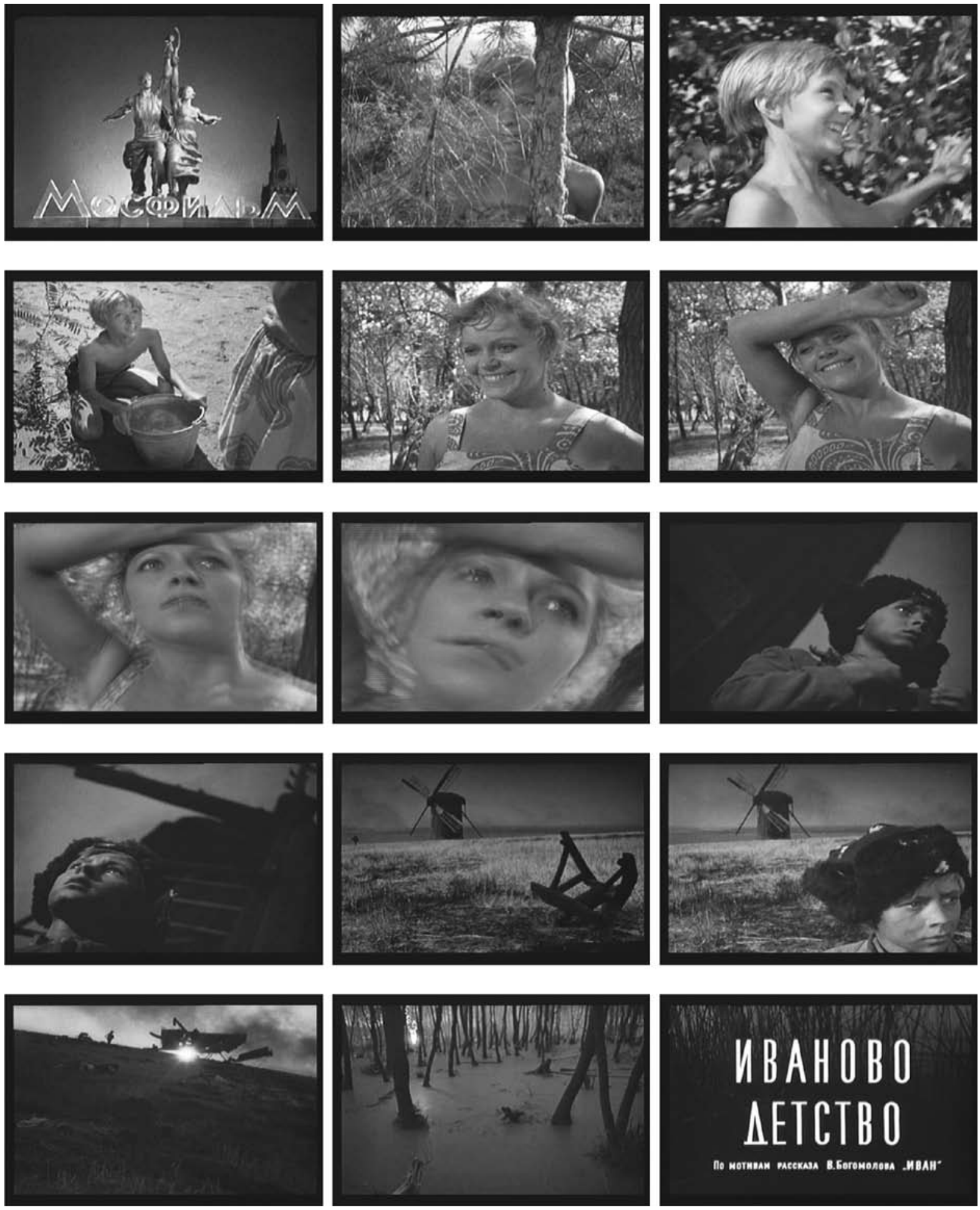

ИBAHOBO
AETCTBO

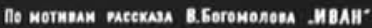




\section{O SOL NEGRO DE ANDRIÊI ARSIÊNIEVICH TARKÓVSKI (OU OS PRIMEIROS QUATRO MINUTOS E VINTE E DOIS SEGUNDOS QUE DEFINIRAM UM CINEMA)}

A clareza de Andriêi Tarkóvski acerca de seu posicionamento ético,suas concepções estéticas e procedimentos formais funda-se em seu primeiro longa-metragem. Conectando-se com a primeira crítica realizada ao seu cinema, pela russa Maia Turóvskaia, esse texto apresenta uma das possíveis chaves para análise da obra tarkóvskiana, percorrendo alguns dos elementos construtivos definidos em "A Infância de Ivan". Embora sua obra tenha amadurecido nos vinte anos seguintes, neste filme operam estratégias de construção de um cinema que evidencia, por um lado, um diálogo intenso com as vanguardas russas que o precederam e, por outro, uma linha de fuga da estética soviética que lhe foi contemporânea.

\author{
Articular historicamente o passado \\ não significa conhecê-lo "como ele de fato foi". \\ Significa apropriar-se de uma reminiscência, \\ tal como ela relampeja no momento de um perigo.
}

1-BENJAMIN, Walter Sobre o conceito da história. In: Walter Benjamin, obras escolhidas. Magia e técnica, arte e política. Vol. 1. Tradução de Sergio Paulo Rouanet. São Paulo: Brasiliense, 1986, p. 244. Título original em alemão: Auswahl in Drei Baenden.
Com seu primeiro longa-metragem, “A Infância de Ivan” (1961), o cineasta russo Andriêi Arsiênievich Tarkóvski ${ }^{1}$ (1932-1986) fez sua iniciação fáustica, passagem entre luz e trevas. O céu tanto é cegado, já no prólogo, pelo esplendor solar, quanto velado pela densa fumaça do fogo que ainda não assentou e transita instável e nervosa, bloqueando pesadamente o brilho do Sol, tornando-o negro. Mudança de um meio ${ }^{2}$ a outro.

Na passagem, o Sol não reflete, mas refrata. Prólogo que, se considerado frente ao conjunto de sua obra, constitui-se em instância continuamente refrativa, cuja estratégia de construção da obra se articulará repetidas vezes, tanto nesse filme, quanto nos seis filmes que se seguiriam.

Sol negro, nesses primeiros minutos e em muitos outros, em que as passagens de um meio a outro se darão, reveste-se de uma qualidade poética irrefutável. O Sol negro tem-se constituído em um signo refrativo nos textos culturais russos, sejam esses textos poemas, pinturas, filmes. Esse constante trânsito de um estado a outro nas artes eslavas parece ter chegado ao seu ápice nas Vanguardas, manteve-se nos porões da censura durante o império do Realismo Socialista do período stalinista e foi abrindo fendas no campo artístico a partir da década de 1960, forçando a percepção da instabilidade e da multiplicidade de olhares sobre um mesmo fenômeno.

Maia Turóvskaia, a primeira dentre os críticos de arte russos a escrever sobre o cinema de Tarkóvski, é quem associa essa passagem de "A Infância de Ivan” à tradição literária e pictórica russa:
1. As palavras russas no corpo do texto foram transliteradas da grafia russa para o português (Brasil) seguindo as normas publicadas no Caderno de Literatura e Cultura Russa pelo Departamento de Línguas Orientais da Universidade de São Paulo (Caderno De Literatura E Cultura Russa. Curso de Língua e Literatura Russa do DLO/ FFLCH da Universidade de São Paulo. São Paulo: Ateliê Editorial, ${ }^{\circ} 1$, mar. 2004). Nas referências bibliográficas mantive a grafia original dos nomes em benefício de investigações futuras.

2. Meio enquanto elemento material, substância ou ambiente. 
3. TUROVSKAYA, Maya. Tarkovsky - Cinema as Poetry. Tradução de Natasha Ward. Londres, Boston: Faber and Faber, 1989. p. 03. (Original russo).

4. Todas as traduções das citações em língua diversa do português foram realizadas pela autora, indicando-se na referência a localização do texto original.

5. Sobre o conceito de refração em Mikhail Bakhtin (V. N.

VOLOCHÍNOV), ver de sua autoria, principalmente:

Marxismo e filosofia da linguagem. Tradução de Michel Lahud e Yara Frateschi Vieira. São Paulo: Hucitec, 1981. (Original russo)

6. Disponível em: http://omnis.if.ufrj. br/ coelho/DI/texto.

html. Acesso:

29 jan. 2007.

7. Disponível em: http://omnis.if.ufrj. br/ coelho/DI/texto. html. Acesso: 29 jan. 2007.
A realidade é a escuridão ameaçadora de um abrigo do qual Ivan deve sair rastejando-se, sem ser percebido. Lá fora estende-se a terra vazia, esmagada. O esqueleto de um moinho de vento levanta seus braços ósseos para o céu, e acima dos campos abandonados um sinistro sintoma da Guerra, a imagem da mata queimada associada a uma ceifeira, preta e terrível na conflagração do pôr do Sol.

Essa conflagração do pôr do Sol é também uma metáfora - firmemente fincada na tradição cultural [russa] que inclui o "Sol do mal" de Urusévski, o "Sol negro" de Sholókov e o eclipse o qual "barrou a passagem" das tropas em "The Lay of Igor's Campaign", como também nos versos de Blok

Sobre o gelo, essa esfera é áspera e vermelha

Como a raiva, a vingança e como o sangue.

(TUROVSKAYA $)^{4}$

Um Sol que se faz negro, em refração. Presentifica-se meio à escuridão, o céu é negro, a terra devastada, o sentido trágico dessa presença solar bloqueada pelas trevas orienta-se na pluralidade de nossos olhares. Tratando-se de signo refrativo, marca sua presença pela refração, ou seja, exige a atenção do espectador e sua resposta diante da instabilidade que propõe; trânsito entre dois mundos, duas instâncias, ao menos duas possibilidades ${ }^{5}$. De qualquer maneira, sua recorrência é o múltiplo, o plural.

A refração é um fenômeno físico, uma mudança da direção de uma onda quando passa obliquamente de um meio a outro e, por isso, ocorre uma mudança em sua velocidade de propagação. Embora o fenômeno seja melhor observável em ondas luminosas, ocorre em diferentes tipos de onda.

Interessa-nos, como ponto de partida, o fenômeno óptico. Um bom exemplo é observar um objeto comprido, como uma colher ou um lápis, em um copo com água pela metade. A parte da colher, ou do lápis, que está na água parecerá estar deslocada da parte que está no ar devido a refração das ondas luminosas. Trata-se de

Uma propriedade de todos os tipos de energia que se movem em ondas, inclusive a luz. As
ondas luminosas em geral se propagam em linha reta, mas quando passam de um material
transparente para outro, elas refratam, ou se desviam. A refração ocorre por que a luz se
move a velocidades diferentes em materiais de diferentes massas específicas ópticas. Quando
a luz que se propaga no ar passa para água, sua velocidade se reduz; assim, a não ser que
penetrem perpendicularmente na superfície da água, os raios luminosos vão se curvar. ${ }^{6}$ A reflexão também é um fenômeno físico, porém não de passagem de um meio ao outro e sim do retorno total ou parcial de um feixe de partículas ou de ondas que se propagam em um determinado meio, após a incidência sobre a superfície que separa um meio do outro. Melhor explicando:

Raios luminosos, como todas as formas de energia que se movem em ondas, podem ser refletidos. Raios de luz são refletidos quando atingem uma superfície brilhante ou espelhada, como uma poça de água ou um espelho. A reflexão envolve dois raios luminosos - o incidente, que parte de um objeto, e o refletido, emitido pela superfície refletora. Os dois raios formam ângulos idênticos em relação à superfície refletora, cada um em um dos lados de uma linha imaginária. ${ }^{7}$ 
A imagem que Tarkóvski constrói não é meramente especular, reflexiva. Antes, reveste-se do caráter refrativo. Há uma persistência de passagens de um meio ao outro na qual o signo - enquanto instância de construção de sentido, articulada pelo artista como elemento de sua obra - antes de apenas refletir, refrata.

Uma análise sobre a produção dos textos culturais soviéticos (realizados em outras linguagens) que foram contemporâneos a Tarkóvski, sob a censura do Estado, nos trará de pronto o desenho autodefinido do Realismo Socialista, ou do que ainda restava dele à época de Tarkóvski, segundo os censores: narrativa linear e objetiva, heroísmo das personagens, concreção histórica. A produção que não auto-refletisse esses signos, canonizados em todas as mídias soviéticas, era desaprovada publicamente com uma palavra emblemática: formalismo.

Citarei um caso exemplar, um pouco anterior à iniciação de Tarkóvski no cinema, mas que em certa medida, assemelha-se à conduta dos censores que lhe foram contemporâneos, embora estes já não fossem os mesmos e o próprio Iosef Stálin (1878-1953) já morrera há muito.

Refiro-me ao compositor Dmítri Dmitriêvich Chostakóvitch (19061975), ao período que sucedeu o término da Segunda Guerra Mundial. Stálin havia lhe encomendado uma sinfonia para comemorar a vitória sobre Adolph Hitler (1889-1945). O compositor, cuja sétima sinfonia ("Leningrado"), feita em 1941, tornara-se o hino popular russo durante a guerra, compôs a nona sinfonia, porém em total desalinho às convenções que se esperavam fossem cumpridas, tratando-se de uma sinfonia em comemoração a uma grande vitória. Sobre essa composição Chostakóvitch assumiu previamente o risco, segundo sua afirmação: "Stálin estava furioso porque a minha sinfonia [a nona] não tinha qualquer ode, qualquer apoteose, sequer uma mísera dedicatória e minha impertinência me custaria caro" $"$.

Dito e feito. Junto aos músicos Nicolai Miaskóvski (1881-1950), Serguiêi Prokofiev (1891-1953), Vissarion Shebalin (1902-1963), Gavriil Popov (19041972) e Aram Katchaturian (1903-1978), Chostakóvitch foi acusado de "formalismo". Os artistas tinham um único dever a cumprir: "A Resolução do Comitê Central do Partido ${ }^{9}$ nos obriga a obedecer às demandas do povo soviético sobre a atividade criativa musical. Nosso dever consiste em mobilizar as nossas forças criativas, e responder ao chamado de nosso grande líder, o camarada Stálin”. Esse foi em parte o Pronunciamento do músico Thikon Khriennikov (1913-), então secretário da União dos Compositores, ao repreender os músicos penalizados em sessão pública. ${ }^{10}$

Chostakóvitch foi afastado do Conservatório de Moscou, onde lecionava há mais de dez anos. Logo após, ainda em 1948, compôs uma ópera onde o seu sarcasmo deu lugar à sátira Rayok. ${ }^{11}$ Nela satiriza "Suliko", canção popular preferida de Stálin, levando ao ridículo a postura da censura diante de qualquer realização que não estivesse de acordo com as normas impostas. Em "Rayok", as
8. "Shostakovich against Stalin", 2005, $00: 54: 26$ a $00: 54: 39$ h.

9. Khriennikov refere-se ao Decreto Jdánov, emitido em fevereiro de 1948 desqualificando e condenando muitos compositores soviéticos. Cabia à União dos Compositores exortar publicamente os músicos a formularem arrependimentos também públicos. Foi o que fez o secretário Khriennikov.

10. "Shostakovich against Stalin", 2005, $00: 55: 53$ a 00:56:04 h.

11. Rayok é palavra russa transliterada cuja tradução mais próxima é Talk-show. 
12. Andriêi Jdánov (1896-1948) era então Secretário do Comitê Central do Partido Comunista na União Soviética.

13. Chostakóvitch referia-se à origem de Stálin, natural da Geórgia, um dos países que ficam na cordilheira do Cáucaso. Suliko é uma canção folclórica georgiana.

14. "Shostakovich against Stalin", 2005, 01:00:57 a 01:03:10 h. personagens de Stálin, Jdánov ${ }^{12}$ e um burocrata cantam:

Stálin:

Camaradas, os compositores do povo

sempre escrevem música realista

enquanto os compositores

contrários ao povo

sempre escrevem música formalista.

Devemos proibir

estes duvidosos experimentos

no campo da música formalista.

Jdánov:

Nas óperas caucásicas, ${ }^{13}$

Lezghinka deve ser veemente,

popular e genuinamente caucásico.

Deve ser autêntico, sempre autêntico,

e apenas autêntico. Sim, sim, sim, autêntico.

\section{Burocrata:}

Isso é o que eu chamo

um discurso científico,

Repleto de idéias profundas! ${ }^{14}$

Embora satíricas, as palavras proferidas em "cena”, no curso da ópera, criticavam a também "encenação" que o Partido determinava para a realização das artes e o conteúdo "científico", ou seja, na visão de Chostakóvitch o "cientificismo" e a "objetividade" exigidos dos artistas encobriam um discurso altamente subjetivo que exaltava os gostos particulares do líder máximo do Partido e seus acólitos.

Segundo o conceito de signo refrativo e reflexivo, a comunicação realizada por qualquer tipo de arte, sob as convenções do Realismo Socialista deveria auto-refletir um conjunto de regras estabelecidas. Tratava-se de um discurso que, por outro lado, não admitia refração. Um discurso que, em última instância, tendia a uma única voz, onde a pluralidade dificilmente encontrava espaço para se manifestar.

Voltemos ao Sol negro de Tarkóvski. Em “A Infância de Ivan” ele aparece logo após a primeira seqüência, que é um sonho (ou uma lembrança da criança), construído sob o efeito de intensa luz, céu aberto, exuberante, em um bosque idílico e na companhia da jovem mãe. Um estrondo terrível é ouvido e a seqüência 
onírica é bruscamente cortada e seguida pela paisagem completamente transtornada, negra, dificilmente distinguida em sua precariedade luminosa e pela abrupta mudança de meio, agora arruinado enquanto nossa percepção ainda estava embebida pela leveza da infância. Foi uma opção inicial bastante audaciosa para um cineasta em início de carreira. No entanto essa opção, com o passar dos anos e amadurecimento de sua obra, se demonstrará como um marca expressiva que inscreverá o seu estilo. Quando realizada no início dos anos 1960, um período de abertura maior por parte da censura, já se demonstrava excêntrica. Em termos de adaptação literária, Tarkóvski começara por contrariar a forma pela qual o conto "Ivan" se inicia, o que não era pouco. Ocorre que ele reivindicava para si, um cineasta estreante, a autoria de um roteiro, ou melhor, o direito de ser autor de um roteiro, em um período em que era a literatura, hierarquicamente, que dominava no cinema soviético. ${ }^{15}$

Explico: "Ivan" é o nome do conto russo de guerra sobre uma criança que perde tudo e passa a trabalhar como espião para o Exército Vermelho. Fora escrito em 1957 pelo soviético Vladímir Bogomolov (1924-2003).

O roteiro inicial, de autoria de Mikhail Papava (1906-1975), começara a ser filmado por outro cineasta soviético. A Mosfilm, ${ }^{16}$ porém, não satisfeita com os primeiros resultados, interrompera as filmagens em outubro de 1960. O trabalho então foi proposto a Tarkóvski, que recém formara-se na VGIK. ${ }^{17}$ Segundo o então jovem diretor, o conto mais se aproximava de um relatório. ${ }^{18}$ Para o cineasta tornar essa linguagem direta e objetiva em linguagem cinematográfica (segundo o seu particular entendimento), deveria enfrentar, em primeiro lugar, uma ordem já constituída para fazer valer a sua própria concepção de cinema e para ter direito de realizar alterações no roteiro, antes e durante as filmagens. E ele o fez, apesar das opiniões contrárias às alterações por ele propostas. A segunda grande mudança foi a introdução de cinco sonhos que se intercalavam com a "realidade". Esse lado "onírico" da história não existia no conto de Bogomolov; essa foi uma interferência bastante acentuada, tratando-se de uma adaptação de texto literário.

Para o novo filme, Tarkóvski propôs então um novo título, "A Infância de Ivan”, um roteiro escrito por ele mesmo e uma nova equipe. Sua proposta foi aceita, não sem resistência e protestos por parte de Bogomolov, que não concordava com as mudanças. ${ }^{19}$

No início do conto de Bogomolov se dá a chegada do garoto ao acampamento militar. Dessa forma direta o espectador fica sabendo que há uma guerra e um garoto órfão que trabalha para os militares soviéticos.

Tarkóvski opta por introduzir a catástrofe da guerra por um outro ponto de vista. E o faz justamente pela transição, pela passagem de meios, de um estado a outro e é nesse momento que define o seu cinema. A inversão inicial à qual me refiro se dá justamente nesse prólogo, nessa passagem da seqüência onírica bruscamente cortada no final por um estampido seco. Não bastasse o som atordoante,
15. TUROVSKAYA, Maya. Op. cit., p. 30

16. A produtora Mosfilm, unidade diretamente vinculada ao Goskino, foi criada em 1923, em Moscou, e foi uma das maiores unidades de produção cinematográfica

soviética. A partir da dissolução da URSS a Mosfilm deixou de ser controlada integralmente pelo estado, passando a ser gerida. também por capital privado (http://www. mosfilm.ru/).

17. VGIK é a mais antiga escola de cinema do mundo, foi criada em 1919, em Moscou. De Instituto de Cinematografia do Estado, em 1986 passou a se chamar Instituto de Cinematografia Gerasimov ttp://www.vgik-edu.ru/ (.Cf. TARKOVSKI, Andreï. CEuvres cinématographiques complètes, tome 1.

Trad. Nathalie Amargier et alli. Paris : Exils, 2001, p. 75. Original russo.

18-TARKOVSKI, Andrei. Esculpiro Tempo. São Paulo: Martins Fontes, 1990. Versão inglesa de: Jefferson Luiz Camargo. Título original em alemão: Die versiegelte Zeit. Gedanken zur Kunst, Ästhetik und Poetik des Films. FrankfurtBerlin: Ullstein, 1985.

19. Cf. TARKOVSKY, Andrei. Collected Screenplays. Tradução de William Powell; Natasha Synessios. London: Faber and Faber, 1999, p. 57-58; TARKOVSKI, Larissa. Andrei Tarkovski.

Paris : Calmann-Lévy, 1998, p. 47-49;

TUROVSKAYA, Maya. Op. cit., p. 01. 
ocorre uma torção da imagem em primeiro plano, do rosto da mãe, que a desfigura por completo.

Mas essa passagem obedece a uma necessidade de refração que se dá literalmente pelo desvio, a imagem sofre uma torção e uma inversão. Notemos o efeito óptico conseguido com o movimento de câmera, com um objetivo poético. Essa figura que parece ser borrada, como se estivesse se desfigurando pela luz no curso de seu próprio movimento de rotação, e nesse giro marcando a película fílmica. Há uma integração dos ritmos sonoros que reverberam, com a figura em rotação: o estertor de uma metralhadora e o grito doloroso e desesperado da criança parecem girar com o corpo em queda e rompem a cadência lírica de um espaço, remetendo-o a outro, conduzindo ao desvio, à refração.

Retomemos o início do filme, após a vinheta prateada da Mosfilm (podemos acompanhar pelo conjunto de frames que ilustram essa seqüência e se encontram logo abaixo). Antes dessa ruptura, desse desvio, em primeiro lugar, o cineasta propõe ao espectador a ativação da memória infantil: tranqüila, doce, permeada por uma luz cuja suavidade banha a leveza dos corpos que se movimentam na tela: a teia de aranha, a árvore, a criança, a cabra, a borboleta, o poço, o balde de água, a mãe; tudo sob o lirismo da banda sonora orquestrada por Katchaturiam e composta por Viatchieslav Ovtchínnikov (1936). E a suavidade do corpo luminoso da criança, embevecida diante da visão idílica, a sensação do vôo: ela mesma uma borboleta, um pássaro, um anjo que está ganhando o espaço aéreo. Ao se aproximar da mãe que caminha com leveza pelo campo, carregando um balde cheio de água, o menino, com o olhar luminoso, conta à mãe que ouvira o canto de um pássaro, um cuco. Sua voz é terna, os movimentos delicados, a mãe lhe sorri docemente, retribui o calor do olhar da criança.

E é justamente durante esse encontro afetuoso e leve que se dá a mudança de meios, a ruptura, o desvio. O espectador choca-se repentinamente com a catástrofe que se abate sobre a criança: a cena idílica é abruptamente atravessada pelo som de um tiro, seguido do giro perverso da imagem da mãe, um corpo agônico, transfigurado, convulso, em queda e o grito desesperado da criança, fora do quadro, quando já não é possível que a mãe o escute e nós, espectadores, completamos mentalmente o quadro, o desespero da criança, o corpo morto da mãe.

A infância perfeita e tranqüila é interrompida, irrevogável e inexoravelmente, pela força da guerra. Justamente essa "infância perfeita" é refratada por outra, a "infância legada pela guerra". Mesmo o título que Tarkóvski escolhe para nomear o seu filme anuncia o seu princípio refrativo: "A infância de Ivan”. A qual infância o autor se refere? Àquela que Ivan teria? Àquela com a qual a criança sonha? Àquela dos tempos de paz? Àquela forjada na guerra? A qual delas?

Muito argutamente sua crítica de primeira hora observa essa estratégia desviante do cineasta. A guerra, segundo observação de Turóvskaia, entra no filme não por sua usual cenografia: não através do rádio, não com barulhos de bombas e 
os vestígios de bombardeios deixados pelos aviões, não com a morte e destruição

(...) Não como a guerra tem sido descrita em tantos filmes soviéticos antes de A Infância de Ivan. A guerra entra no filme enquanto o coração está se lembrando, como um súbito e doloroso abalo brutal para a imaginação, quando a face da mãe é arremessada de cabeça para baixo de repente... 20

Imagem e som engenhosamente preparados para o público. Tarkóvski se utiliza da imagem e do som para provocar as lembranças, não de uma forma descritiva, mas propondo ao espectador uma imersão no tempo através de percepções, através do que teorizaria de forma abrangente como sendo "associações poéticas". ${ }^{21}$

Nos primeiros quatro minutos e vinte e dois segundos do filme ele constrói minuciosamente a refração, a passagem entre um meio e outro para a percepção do desvio: entre a paz e a guerra; a infância na paz, roubada pela guerra e o eclipse de sua ausência. Nada é feito ao acaso, as gradações de luz, o movimento das personagens no quadro, o som, os elementos gráficos, desde a vinheta da Mosfilm até a entrada do título e créditos do filme. O prólogo, antes da entrada dos créditos diz a que o filme veio e define, ao mesmo tempo, o caminho percorrido não apenas por Ivan, mas por Andriêi Arseniêvich Tarkóvski.

"A Infância de Ivan" deveria ter sido apenas mais um filme de guerra, em meio a tantos produzidos em todos os cantos do mundo e na Rússia, até a exaustão. Não foi. Iniciou-se controvertendo a ordem dos códigos de construção de um filme desse gênero. Seria então um filme circunscrito a um período (o da guerra) e a um país (a Rússia no contexto da União Soviética)? Se não, o que mantém esse filme constantemente atualizado, fazendo-o chegar aos nossos dias, longe da Segunda Guerra e distante mesmo da União Soviética que nem mais existe enquanto configuração geopolítica? $\mathrm{O}$ que o faz atualizado e ao mesmo tempo deslocado e desenraizado -- porque esse prólogo poderia ser de qualquer outra guerra do terceiro milênio -- e, ao mesmo tempo, tão entranhado em seu próprio tempo e cultura?

Retomando e seguindo a análise de Turóvskaia, mas estendendo-a, observo que Tarkóvski, nessa primeira seqüência, alinha-se e renova a poética exercitada pelas Vanguardas Russas. Ou seja, Tarkóvski se aproxima das Vanguardas não para imitá-las. Sua aproximação se dá no exercício de construção da obra, no ato de se apropriar de determinados procedimentos vanguardistas e deslocálos para o tempo futuro, atualizando-os, estendendo-os a novas possibilidades de sentidos.

Vejamos esse breve trecho do poema de Osíp Mandelstam (1991-1938), justamente nomeado "Sol negro":

A voz dos hebreus tinia

sobre minha mãe e, imerso

no fulgor do negro sol
20. TUROVSKAYA,

Maya. Op. cit., p 03.

21. TARKOVSKI, Andrei. Esculpir 0

Tempo. São Paulo:

Martins Fontes, 1990 
22. Slavutzky, Abrao. A paixão de ser - depoimentos e ensaios sobre a identidade judaica. Porto Alegre: Artes e Ofícios, 1998.

23. BENJAMIN, Walter. Op. cit., 225. eu despertei no meu berço.

$(\text { Slavutzky })^{22}$

O Sol negro das Vanguardas de Blok, de Mandelstam, em Tarkóvski se estende no tempo, amplia sua complexidade estética e comunicativa à medida que questiona a todo instante a qualidade da luz, a vertigem da imagem que pode tanto ser arrebatadora quanto completamente ruinosa. Sol negro que refrata inclusive a História, luminosa e plena dos vencedores que, na definição de Walter Benjamin (1892-1940), constitui-se em "um monumento da barbárie". ${ }^{23}$ Essa História, que seria a história da guerra dos vencedores, do heróis de guerra (afinal os russos venceram dura e corajosamente os nazistas, depois de uma longa luta), é refratada pelas trevas históricas, aquele pedaço de dor terrena que nunca é iluminado. Tarkóvski ilumina inicialmente a infância de Ivan, aquela que poderia ter sido luminosa e plena, apenas para depois refratar com essa figura perversa, esse Sol negro; aprofundando na alma as dores da tragédia humana, das quais as luzes da História se evadem.

O Sol negro pode ser considerado um signo refrativo expandido, atravessador de fronteiras, mergulhado no tempo. Tanto é combustão como memória, ou coloca em combustão a memória. E aqui sua acepção tem o sentido expandido de conceito à figura, de figura à opção artística que vai refigurar esse Sol negro em outras seqüências, em outros filmes, até a combustão final que é o incêndio no último filme de Tarkóvski, "O Sacrifício" (1985). Em todas essas figuras, refiguras e desfiguras a beleza pungente e trágica das imagens em movimento se não salvam o mundo, evocam sua lembrança, suplicando-lhe a não esquecer, não esquecer, não esquecer.

Como opção artística o seu lirismo é ácido, o seu classicismo corrosivo e sua beleza terrível. A esperança se faz em paradoxo, nas asas de um anjo caído, submerso em águas lamacentas ("Infância de Ivan", "Nostalgia", "Stalker"); no frescor da infância quando essa já está irremediavelmente perdida ("A Infância de Ivan"); na vastidão de um céu ("A Infância de Ivan”, "Rublióv", "Solaris", "Stalker", "O Sacrifício") inalcançável e inconcebível em sua grandeza, diante dos pequenos corpos terrenos, dando a proporção da dimensão humana e limitada, finita. Então nos recolhemos atemorizados pois nessa vastidão inconcebível se dispersam todos os nossos desejos, um a um, sem que consigamos alcançá-los, por mais que corramos e tentemos retê-los (final de "A Infância de Ivan”). Não há possibilidade de exorcismo, ainda que nos mantenhamos como Rublióv, no mais profundo silêncio. Temos que nos encontrar cara a cara com esse Sol negro que nos persegue, nos habita e nos coloca diante de um terrível abismo, pronto para acolher nosso salto mortal, mas dificilmente nos arriscamos a saltar.

Demonstrar ainda que seja uma mínima possibilidade de libertação é um ato excêntrico dentro das sociedades humanas regidas pelos princípios totalitários, 
de qualquer tipo que seja esse totalitarismo. E Tarkóvski o fez não pela abstração: o seu cinema é físico, terreno, cósmico, mineral, matérico e por isso mesmo nos alcança, incomoda, fascina e, ao mesmo tempo, apavora. Porque a liberdade não está restrita a heróis, a glórias à magnificência. Então que liberdade é essa que já nos afasta da doxologia e de cara nos demonstra, em primeiro plano, uma luz refratada pela escuridão? Luz que inscreve rigorosa, com um zelo obsessivo, cena a cena, em uma dança fáustica que nos atinge como um ferro em brasa. Tanto esmero para nos mostrar, com esse Sol negro, o lado oculto da ordem, o que está por trás desse cadinho de realismo das aparências (seja socialista, nazista, fascista, capitalista, etc.) que se dissemina anestesiante e se transmuta sedutor em meios tons, meias verdades, meias vidas.

Onde e quando se exigia civismo, Olieg Iankóvski (1944), ator russo que trabalhou com Tarkóvski em "O Espelho" e "Nostalgia”, define com perspicácia a obra do cineasta como sendo: "o logro cívico e artístico de Tarkóvski que comoveu nossa memória, esquadrinhou nossas feridas e nossas iniludíveis e ignoradas culpas". ${ }^{24}$

O Sol negro se reconfigura também em "Nostalgia", nas seqüências finais, quando já não há mais nada que se possa fazer. A Rússia, para Andriêi (Gortchacóv) está tragicamente perdida, uma luz cheia e plena que a distância encobriu. A Rússia da qual Andriêi se afasta, permanecendo na Itália, é um tempo cravado em um espaço físico, cujos sentidos se convulsionam na memória e se perdem em nostalgia. O retorno físico é inconcebível porque suas possibilidades são ceifadas pela morte. Contra o retorno físico do escritor à sua terra natal Tarkóvski interpõe o inevitável: Andriêi Gortchacóv morre no mesmo instante em que seu amigo Domênico; após tentar e, por fim, conseguir a façanha de atravessar uma piscina seca levando uma pequena vela acesa na mão, evitando que o fogo se apagasse. Domênico, por sua vez, oferecera-se em sacrifício, à combustão da matéria e dos sentidos. É o seu corpo, de casaco e gorro negros que rola, em chamas, do alto da escultura de Michelangelo na Praça São Marcos, em Roma. O Sol negro reconfigurado em incêndio, em sacrifício humano, para quê? Para nada. O estigma da reconfiguração está na força da memória reativada pela arte. Aí o artista inscreve sua missão de Sísifo: lembrar ao humano do que ele eternamente se esquece. E aí o galope dialogante com os tempos, com a cultura planetária.

Tarkóvski aumenta o índice de refração adensando o meio. A renovação de sentidos se dá no desvio, na assimetria. E o sacrifício final se encobre de presságios: no campo escuro, eclipsadas, as mulheres russas sob a face oculta da Lua estão aparentemente imóveis, mas recolhidas e apreensivas como os animais. Novamente em "Nostalgia”, como fora em “A Infância de Ivan”, a passagem entre um meio e outro. O mundo diurno, o mundo noturno. O campo da realidade, o campo do sonho, do delírio, da loucura. Em "Nostalgia", mais do que em "A Infância de Ivan”, porém, essa passagem é dolorosíssima. Ela já não se dá mais
24. TARKÓVSKAYA,

Marina. Acerca de Andrei Tarkovski. Tradução de J. L. Aragon, J. Gil Fernández y T. Pérez Hernández. Madrid: Ediciones Jaguar, 2001, p. 177. (Original russo). 
25. "Templo romano

dedicado a Júpiter Capitolino, edificado no cume de uma das colinas da cidade; em sentido mais amplo, a própria colina,

incluídos o templo e a fortaleza” (Cf. HOUAISS).

26. Períodos que se seguiram à morte de Stalin caracterizados por uma semi-abertura, um afrouxamento

da censura (Degelo) e um posterior recrudescimento desta (Estagnação).

27. Abreviação de Proletrskaya Kultura ou Cultura Proletária, organização surgida na

União Soviética em 1917 objetivando fundar uma arte verdadeiramente proletária, livre das influências da arte burguesa (DITL, http://www.ditl.info/ Acesso: 29 jan. 2007).

28. TARKÓVSKAYA, Marina. Op. cit. p. 52-53. no campo da guerra. Ela se dá em uma praça pública, em um dos centros que já fora o centro do mundo civilizado, o Capitólio. ${ }^{25}$ Por que, para que e para nada são tanto perguntas como respostas, uma refrata a outra, combustão total. Em "Nostalgia", ao contrário de "O Sacrifício", a salvação é por um mundo que não quer ser salvo. Tanta quietude sob essa estranha esfera estelar. Prepara-se o desvio e é certo, sob esse escuro céu sobre o campo russo, que Andriêi jamais retornará.

Retomemos então o fio inicial. A clareza de Tarkóvski sobre suas concepções estéticas e procedimentos formais no cinema funda-se em "A Infância de Ivan”. Embora sua obra tenha amadurecido durante os vinte anos de carreira, esse seu primeiro longa-metragem contém em si os conceitos principais que a norteariam. Isso o demonstra sua obra, corroborada por todas as suas entrevistas, depoimentos de membros de sua equipe, e seus próprios escritos. Ou seja, Tarkóvski funda o seu centro e a partir daí desenvolve o seu estilo norteado pela passagem de um meio a outro, refratando, estabelecendo um ritmo próprio. Contrapõem-se, objetivamente, aos alicerces que sustentaram a estética do Realismo Socialista, auto-reflexivo, no período stalinista e contrapõem-se também, aos menos claros, mas ainda assim dogmáticos princípios dos períodos do Degelo e da Estagnação, ${ }^{26}$ igualmente subsidiados pelas convenções do Realismo Socialista.

Aleksandr Misharin (1939), escritor russo, amigo e colaborador de Tarkóvski desde 1964, afirma que o cineasta sempre dizia:

\begin{abstract}
Posso fazer algo bom baseado apenas em três coisas: o sangue, a cultura e a história. Sangue, cultura e história, os três foram violados durante os tempos do Proletkult ${ }^{27}$, quando uma intelligentsia desaparecia para dar lugar a outra nova, quando foi criada uma nova indústria cinematográfica com critérios diferentes. Andriêi [Tarkóvski] foi o primeiro que tentou fazer algo contra essa ruptura, conseguiu construir uma ponte entre as culturas (...) Seu outro grande serviço foi que restabeleceu o elo entre o passado e o presente e inoculou na cultura cinematográfica a qualidade do eterno. ${ }^{28}$
\end{abstract}

Ponte entre culturas diversas, em espaços e tempos distintos, seu cinema pede também a refração de nosso olhar, senão como seria possível que, antes que esses quatro curtíssimos minutos terminem, recolhamos da tela apenas a visão da inocência e da beleza e não vislumbremos essa inversão impiedosa e cruel, que se dá em todas as instâncias, nessa passagem? Como compreender todos os ícones russos (e pinturas européias renascentistas) da Virgem que se seguirão, um a um até o fim, por todos os seus filmes, sem reconhecer-lhes a assimetria com esse primeiro ícone cinematográfico, pintado em luz, sonorizado? O pequeno Ivan ajoelhado aos pés da mãe, logo depois morta. Trata-se de um Stabat mater invertido. Como se sabe, a cena descrita no Evangelho de São João (19, 25 a 28), refere-se à Mãe aos pés da cruz de Seu Filho. E, no entanto, nesse prólogo de filme, eis a inversão: aqui é o filho, pequeno, frágil aos pés de sua mãe; criança que logo após despertará "imerso no fulgor do negro Sol". 
Sol negro que se converterá em Solaris, oceano fulgurante e tempestuoso, o líquido primordial onde a esperança não se prende à superfície, mas mergulha no escuro de suas profundezas. Que novos corpos de sentido se originariam desse, fluidificado em oceano? Talvez os desejos mais obscuros a se materializarem tanto na Zona, em "Stalker" quanto no próprio Oceano de "Solaris"; desejos que estão em nossa mais recôndita e insondável memória, aqueles pelos quais lavamos com ácido o painel de nossas lembranças, em vão. Eles retornam, nos revisitam materializados diante de nós: verbo se fazendo carne. Vez por outra são trazidos por poetas, escritores, filósofos, pintores, atores, cineastas. Aqueles que se agitam e se matam para nos lembrar que estamos eternamente condenados à nossa liberdade e por ela somos responsáveis.

\section{Referências Bibliográficas}

\section{Filmes/Vídeos (DVD)}

A Infância de Ivan (1961). Direção: Andrei Tarkovski. Roteiro: Mikjail Papava e Vladimir Bogomolov. Intérpretes: Kolia Burlaiev, Valentin Zubkov, Evgueni Zharikov, Andrei M. Konchalovski. Direção de arte: Yevgueni Tcherniaiev. Fotografia: Vadim Yusov. Música: Vitcheslav Ovitchinnikov. Continental. Edição: G. Natanson. Produção: Mosfilm. Continental Home Video. DVD (90 min.), 4:3, cor/pb, NTSC, dolby digital 2.0 e 5.1, em russo. Legendas: português, inglês e espanhol. Título original em russo: Ivanovo Destvo.

\section{ANDREI RUBLEV, "THE PASSION ACCORDING TO ANDREI"} (1966). Direção: Andrei Tarkovsky. Roteiro: Andrei Tarkovsky; Andrei MikhalkovKonchalovsky. Direção de arte: E. Chernyaev, E. Novoderezhkin, S. Voronkov. Intérpretes: Anatoly Solonitsin, Ivan Lapikov, Nikolai Grinko, Nikolai Sergeyev, Irma Raush Tarkovskaya, Nikolai [Kolya] Burlaev. Fotografia: Vadim Yusov. Música: Viacheslav Ovchinnikov. Edição: Ludmila Feignova. Produção: Mosfilm. The Critherion Collection. DVD (205 min.), 2.35: 1, cor/pb, NTSC, dolby digital; mono, em russo. Legendas: inglês. Título original em russo: Strasti pa Andrieiu.

SOLARIS (1972). Direção: Andrei Tarkovski. Roteiro: Andrei Tarkovski, Friedrich Gorenstein. Direção de Arte: Mikhail Romadin. Intérpretes: Natalia Bondartchuk, Donatas Banionis, Anatoli Solonitsyn. Fotografia: Vadim Yusov. Música: Eduard Artemiev, J. S. Bach. Edição: Ludmila Feignova. Produção: Mosfilm. Continental Home Video. DVD (166 min.) dual layer, 16:9 widescreen anamórfico, cor/pb, NTSC, dolby digital 2.0, em russo. Legendas: português, inglês e espanhol. Título original em russo: Saliaris. 
O ESPELHO (1974). Direção: Andrei Tarkovski. Roteiro: Andrei Tarkovski, Aleksandr Misharin. Direção de Arte: Nikolai Dvigubski. Intérpretes: Margarita Terékhova, Filip Yankovski, Ignat Daniltsev, Oleg Yankovski, Yuri Nazarov. Fotografia: Gueorgi Rerberg. Música: Eduard Artemiev, J. S. Bach, H. Purcell, G. B. Pergolesi. Edição: Ludmila Feignova. Produção: Mosfilm. Continental Home Video. DVD (101 min.) dual layer, 4:3 fullscreen, cor/pb, NTSC, dolby digital 2.0, em russo. Legendas: português, inglês e espanhol. Título original em russo: Zierkalo.

STALKER (1979). Direção: Andrei Tarkovski. Roteiro: Andrei Tarkovski, Arkadi e Boris Strugatski. Direção de Arte: A Merkúlov. Intérpretes: Anatoli Solonitsyn, Alexandr Kaidanovski, Nicolái Grinko, Alissa Freindikh, Natasha Abramova. Fotografia: Aleksandr Kniajinski. Música: Eduard Artemiev, Ravel, Beethoven. Edição: Ludmila Feignova. Produção: Mosfilm. Continental Home Video. DVD (134 min.) dual layer, 4:3 fullscreen, cor/pb, NTSC, dolby digital 2.0, em russo. Legendas: português, inglês e espanhol. Título original em russo: Stalker.

NOSTALGIA (1983). Direção: Andrei Tarkovski. Roteiro: Andrei Tarkovski, Tonino Guerra. Direção de Arte: Andrea Crisanti. Intérpretes: Oleg Yankovski, Erland Josephson, Domiziana Giordano, Patrizia Terreno. Fotografia: Giuseppe Lanci. Música: Beethoven, Debussy, Verdi, Wagner. Edição: Erminia Marani, Amadeo Salfa, Roberto Puglisi. Produção: Sov Film (União Soviética); Rai 2 TV (Itália). Continental Home Video. DVD (121 min.) dual layer, 4:3 letterbox, cor/pb, NTSC, dolby digital 2.0, em russo e italiano. Legendas: português, inglês e espanhol. Título original em russo: Nostalghia.

LE SACRIFICE (1986). Direção: Andrei Tarkovski. Roteiro: Andrei Tarkovski. Direção de Arte: Anna Asp. Intérpretes: Erland Josephson, Susan Fleetwood, Valérie Mairesse, Allan Edwall, Gudrun S. Gisladottir, Sven Woller, Filippa Franzén, Tommy Kjllqwist. Fotografia: Sven Nykvist. Música: JeanSébastien Bach, Watazumido-Shuso, Chants de bergers de Dalécarlie et de Härjedalen. Edição: Andrei Tarkovski; Michal Leszczylowski. Produção: Argos Films (Paris) Svenka Filminstitutet (Stockholm). Argos Films. DVD (142 min.), 14:3, cor/pb, mono orig., em sueco. Legendas: francês. Título original em russo: Offret.

SHOSTAKOVICH AGAINST STALIN, THE WAR SYMPHONIES (2005). Direção: Larry Weinstein. Direção musical: Valery Gergiev. Com: Netherlands Radio Philharmonic; Kirov Orchestra. Produção: Rhombus Media/ ZDF German Television Network/ARTE; IDTV Cultuur. Phillips Classics. DVD 
(76 min.), 16:9 anamorphic, cor/pb, NTSC, LPCM Stereo e DTS 5.1, em inglês e russo. Legendas: Inglês, francês, alemão, italiano, espanhol e chinês.

Neide Jallageas é pesquisadora brasileira com mestrado em Estética e Comunicação do Audiovisual pela Escola de Comunicações e Artes da Universidade de São Paulo e doutoramento em Comunicação e Semiótica pela Pontifícia Universidade Católica de São Paulo, com tese sobre o cinema de Andriêi Tarkóvski. Realiza ainda trabalhos experimentais na área de fotografia e vídeo desde 1996, com obras em acervos dos principais museus brasileiros. 